\title{
Association of 17 Definitions of Remission with Functional Status in a Large Clinical Practice Cohort of Patients with Rheumatoid Arthritis
}

\author{
Pedro D. Carvalho (i), Ricardo J.O. Ferreira (D), Robert Landewé, David Vega-Morales, \\ Karen Salomon-Escoto, Douglas J. Veale, Arvind Chopra, José A.P. da Silva, \\ and Pedro M. Machado (i)
}

ABSTRACT. Objective. To compare the association between different remission criteria and physical function in patients with rheumatoid arthritis followed in clinical practice.

Methods. Longitudinal data from the METEOR database were used. Seventeen definitions of remission were tested: American College of Rheumatology/European League Against Rheumatism (ACR/EULAR) Boolean-based; Simplified/Clinical Disease Activity Index (SDAI/CDAI); and 14 Disease Activity Score (DAS)-based definitions. Health Assessment Questionnaire (HAQ) $\leq 0.5$ was defined as good functional status. Associations were investigated using generalized estimating equations. Potential confounders were tested and sensitivity analyses performed.

Results. Data from 32,915 patients (157,899 visits) were available. The most stringent definition of remission was the ACR/EULAR Boolean-based definition (1.9\%). The proportion of patients with HAQ $\leq 0.5$ was higher for the most stringent definitions, although it never reached $100 \%$. However, this also meant that, for the most stringent criteria, many patients in nonremission had HAQ $\leq 0.5$. All remission definitions were associated with better function, with the strongest degree of association observed for the SDAI (adjusted OR 3.36, 95\% CI 3.01-3.74).

Conclusion. The 17 definitions of remission confirmed their validity against physical function in a large international clinical practice setting. Achievement of remission according to any of the indices may be more important than the use of a specific index. A multidimensional approach, targeted at wider goals than disease control, is necessary to help all patients achieve the best possible functional status. (First Release September 1 2019; J Rheumatol 2020;47:20-7; doi:10.3899/jrheum.181286)

Key Indexing Terms:

RHEUMATOID ARTHRITIS DISEASE ACTIVITY DISEASE ACTIVITY SCORE REMISSION

\footnotetext{
From the Rheumatology Department, Centro Hospitalar Universitário do Algarve, Faro; Lisbon Academic Medical Center, Lisbon; Algarve Biomedical Center, Faro; Health Sciences Research Unit: Nursing (UICiSA:E), Escola Superior de Enfermagem de Coimbra, Coimbra; Coimbra Institute for Clinical and Biomedical Research (iCBR), Faculty of Medicine, University of Coimbra, Coimbra; Rheumatology Department, Centro Hospitalar Universitário de Coimbra, Coimbra, Portugal; Amsterdam Rheumatology Center, Amsterdam University Medical Center $(U M C)$; Zuyderland Medical Center, Heerlen, the Netherlands; Hospital Universitario “Dr. José Eleuterio González”/Universidad Autónoma de Nuevo León, Monterrey, Mexico; University of Massachusetts Medical School, Rheumatology Center, Worcester, Massachusetts, USA; Dublin Academic Medical Centre, Dublin, Ireland; Centre for Rheumatic Diseases, Pune, India; Centre for Rheumatology Research, and Medical Research Council (MRC) Centre for Neuromuscular Diseases, University College London, London; Rheumatology Department, Northwick Park Hospital, London North West University Healthcare National Health Service (NHS) Trust, London, UK.

This study was supported by a research grant from the MERIT Foundation (www.meteorfoundation.com). P.M. Machado was supported by the National Institute for Health Research (NIHR) University College London Hospitals Biomedical Research Centre. The views expressed are those of the authors and not necessarily those of the NHS, the NIHR, or the UK Department of Health.

P.D. Carvalho, MD, Rheumatology Department, Centro Hospitalar Universitário do Algarve, and Lisbon Academic Medical Center, and
}

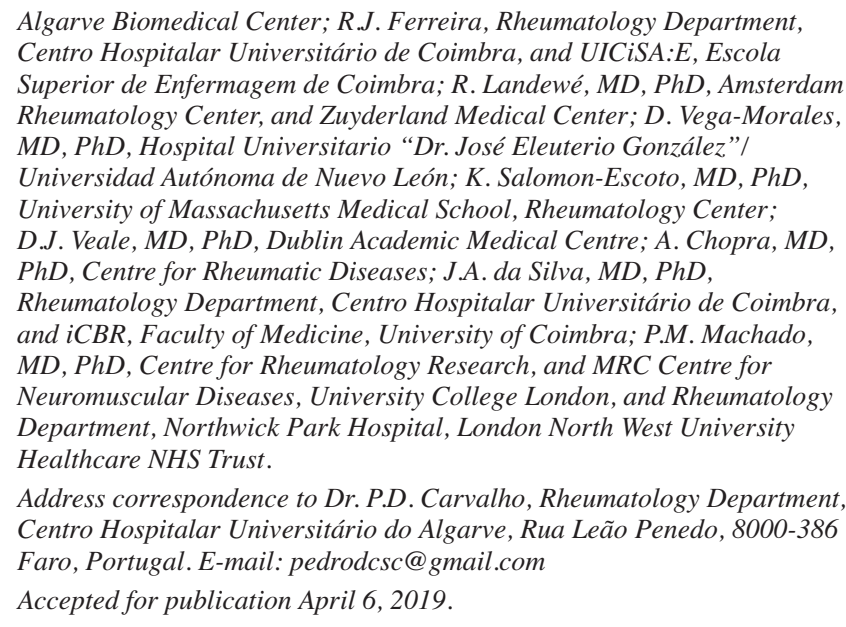
Centro Hospitalar Universitário de Coimbra, and UICiSA:E, Escola Superior de Enfermagem de Coimbra; R. Landewé, MD, PhD, Amsterdam Rheumatology Center, and Zuyderland Medical Center; D. Vega-Morales, MD, PhD, Hospital Universitario "Dr. José Eleuterio González"/ Universidad Autónoma de Nuevo León; K. Salomon-Escoto, MD, PhD, University of Massachusetts Medical School, Rheumatology Center; D.J. Veale, MD, PhD, Dublin Academic Medical Centre; A. Chopra, MD, PhD, Centre for Rheumatic Diseases; J.A. da Silva, MD, PhD, Rheumatology Department, Centro Hospitalar Universitário de Coimbra, and iCBR, Faculty of Medicine, University of Coimbra; P.M. Machado, $M D, P h D$, Centre for Rheumatology Research, and MRC Centre for Neuromuscular Diseases, University College London, and Rheumatology Department, Northwick Park Hospital, London North West University Healthcare NHS Trust.

Address correspondence to Dr. P.D. Carvalho, Rheumatology Department, Centro Hospitalar Universitário do Algarve, Rua Leão Penedo, 8000-386 Faro,Portugal.E-mail:pedrodcsc@gmail.com

Accepted for publication April 6, 2019.

Significant advances in the management of rheumatoid arthritis (RA) have taken place in the last few decades, allowing the establishment of remission as the target of treatment in clinical trials, and in routine clinical practice ${ }^{1,2}$. 
In spite of the existing agreement concerning the importance of achieving remission to prevent joint destruction and functional disability, there is still no consensus regarding the definition of such a goal. Ideally, remission should represent an absence or a very low state of disease activity, and should be validated against a longterm outcome, such as physical function or radiographic progression. The stringency of such a threshold will obviously influence the percentage of patients who reach it $2,3,4,5,6,7$.

Several definitions of remission have been proposed, including the American College of Rheumatology/European League Against Rheumatism (ACR/EULAR) definition and others based on composite indices such as the Disease Activity Score (DAS) with multiple variations and proposed cutoffs, the Clinical Disease Activity Index (CDAI), and the Simplified Disease Activity Index (SDAI) ${ }^{1,2,7}$.

A total of 17 definitions of remission in RA can be found in the literature, all of them validated to some extent. These definitions refer to the ACR/EULAR, CDAI, SDAI, and those definitions based on DAS and the 28-joint count DAS (DAS28); each one encompassing information on C-reactive protein (CRP) or erythrocyte sedimentation rate (ESR) and considering or not considering patient's global assessment $(\mathrm{PtGA})^{8-15}$. In addition, the newest cutoffs for DAS28 were also added to the analysis. However, in previous studies, the number of definitions compared, patient numbers, or duration of followup were limited and few reports related remission to functional status. Moreover, most previous studies came from single centers or culturally homogeneous groups and none directly compared the full list of definitions, some of which were published in the last year (e.g., newly proposed DAS28 cutoffs) ${ }^{14,15}$.

The aim of our present study was to compare the prevalence of remission according to various criteria and to study the relationship between remission and physical function in a large multinational cohort of real-life patients with RA.

\section{MATERIALS AND METHODS}

For this study, longitudinal data from the Measurement of Efficacy of Treatment in the Era of Outcome in Rheumatology (METEOR) database were used. METEOR is a software tool, designed by and for rheumatologists, available online for free, which allows longitudinal registration of disease activity and disability measures. Data can either be entered directly on the online tool or uploaded from local electronic health record systems or registries. Details of the METEOR tool have been previously described $^{16,17,18}$. The database used in this work included visits from June 1985 until November 2015.

Seventeen definitions of remission were tested: the ACR/EULAR Boolean-based definition of remission [tender joint count $\leq 1$, swollen joint count $\leq 1, \mathrm{CRP} \leq 1 \mathrm{mg} / \mathrm{dl}$, and PtGA $\leq 1$ (on a $0-10$ scale)], SDAI $\leq 3.3$, $\mathrm{CDAI} \leq 2.8$, and the 8 definitions based on DAS or DAS28. Those 8 definitions were the DAS score $<1.6$ (definition with ESR or CRP), DAS28 score < 2.6 (definition with ESR or CRP), always dichotomizing for PtGA (i.e., 3 or 4 variables). In addition, the newly suggested cutoffs were also considered: DAS28-CRP $<1.9$ (calculated vs SDAI), DAS28-ESR $<2.2$ (calculated vs SDAI), and DAS28-CRP $<2.4$ (calculated va DAS28-ESR $)^{14,15}$. Disability was measured by the Health
Assessment Questionnaire (HAQ) and HAQ $\leq 0.5$ defined as "good functional status" 19

Associations were investigated through generalized estimating equations (GEE), using $\mathrm{HAQ} \leq 0.5$ as the dependent variable and the various remission criteria as independent variables. GEE allow the combination of multiple measurements per patient and use all available data during followup, while taking into account missing values and correcting for within-patient correlation $^{20}$. With GEE, each visit counts as an independent assessment and is used to classify the remission status of the patient, which may change over time. However, GEE allows the use of all longitudinal data because it takes the dependency of observations (within subject/patient-correlation) into account. Models were adjusted for potential confounders: treatment with biological disease-modifying antirheumatic drugs (bDMARD), body mass index, age, sex, smoking status, gross national income per capita, disease duration, anticitrullinated peptide antibody status, rheumatoid factor status, and presence of erosions. Sensitivity analyses were performed using sets of data limited to first visits only and to patients with no missing data for all definitions of remission. A flow chart representing the number of patients and visits taken into consideration in the various subanalyses is presented in Figure 1 . The METEOR registry contains completely anonymized data that were gathered during daily practice. There is no link between the anonymized data and the original patient identity, according to current General Data Protection Regulation. Treatment, timing of followup visits, and measurements were non-protocolled. Therefore, medical ethics board approval was not required.

\section{RESULTS}

Study population. Data from 32,915 patients and 157,899 visits were available (average $6.9 \pm \mathrm{SD} 7.9$ visits/per patient). The sociodemographic and clinical characteristics at the first visit are described in Table 1, for all patients and for those with information about all definitions of remission $(\mathrm{n}=9902)$. Regarding treatments, $42.2 \%$ were receiving corticosteroids, $72.8 \%$ conventional synthetic DMARD, and $11.1 \%$ bDMARD. The mean HAQ was 1.0 (SD 0.8; Table 1).

Data were not available for all patients; the number of patients with valid information for each variable at the first visit is presented in Table 1.

The study population resulting from this international initiative assembled patients from different countries as presented in Supplementary Table 1 (available with the online version of this article).

Fulfillment of the definitions of remission. The most stringent definitions of remission, as observed in the first METEOR visit, were the ACR/EULAR Boolean-based definition $(1.9 \%)$ and the SDAI $\leq 3.3(6.1 \%)$. Regarding the various remission criteria based on the DAS, the percentages of first visits in remission ranged between $6.5 \%$ [for the newly proposed DAS28-CRP(3v) cutoff of 1.9] and 20.4\% [for the DAS-ESR(4v) cutoff of 1.6; Table 2].

Remission data taking all visits into account are also presented in Table 2. As expected, the percentage of visits with patients in remission increased at followup. The most stringent definitions of remission in this analysis were the ACR/EULAR Boolean-based definition (4.5\%) and the CDAI (13.4\%). The percentage of visits in SDAI remission was $17.1 \%$, and regarding the various remission criteria

Personal non-commercial use only. The Journal of Rheumatology Copyright @ 2019. All rights reserved. 


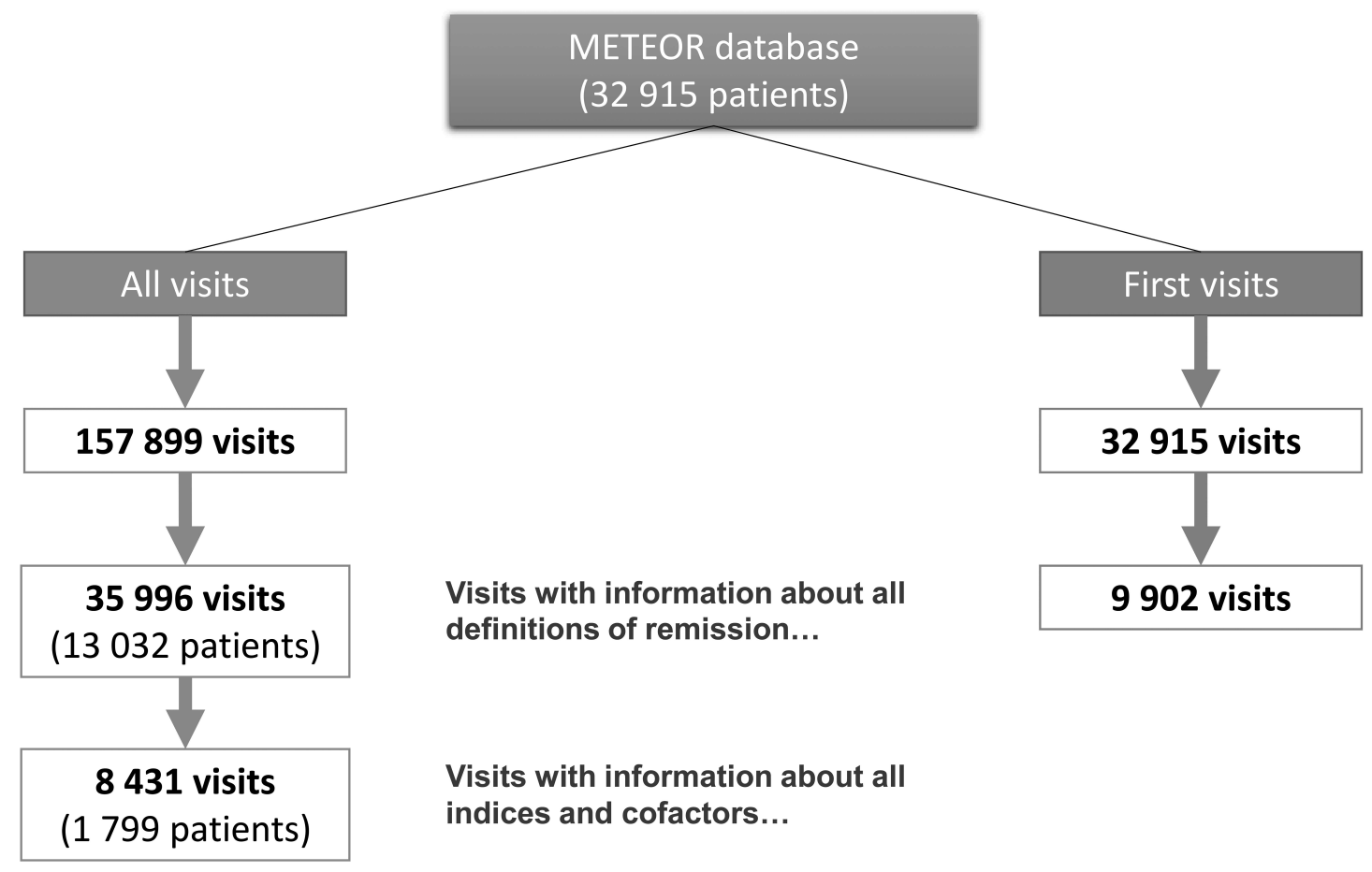

Figure 1. Flow chart representing the number of patients and visits taken into account in the analyses performed. METEOR: Measurement of Efficacy of Treatment in the Era of Outcome in Rheumatology.

Table 1. Summary of the clinical and demographic characteristics of the study population at first visit.

\begin{tabular}{|c|c|c|c|c|}
\hline \multirow[t]{2}{*}{ Characteristics } & \multicolumn{2}{|c|}{ All Patients, $\mathrm{n}=32,915$} & \multicolumn{2}{|c|}{$\begin{array}{l}\text { Patients with Full Information on All } \\
\text { Definitions of Remission, } n=9902\end{array}$} \\
\hline & & N1 & & $\mathrm{N} 2$ \\
\hline Age at visit, yrs & $53.0 \pm 14.8$ & 32,089 & $50.4 \pm 14.0$ & 9701 \\
\hline Disease duration, yrs & $7.2 \pm 8.4$ & 25,448 & $6.8 \pm 7.9$ & 8828 \\
\hline $\mathrm{BMI}, \mathrm{kg} / \mathrm{m}^{2}$ & $26.5 \pm 5.2$ & 13,551 & $26.1 \pm 5.3$ & 4444 \\
\hline ACPA-positive & $11,229(70.3)$ & 15,981 & $3651(74.3)$ & 4916 \\
\hline Erosions & 8611 (53.7) & 16,027 & $2693(55.9)$ & 4820 \\
\hline Treatment with bDMARD & $3660(11.1)$ & 32,915 & $889(9.0)$ & 9902 \\
\hline TJC28, n & $8.6 \pm 9.3$ & 29,908 & $11.2 \pm 9.8$ & 9902 \\
\hline $\mathrm{SJC} 28, \mathrm{n}$ & $4.0 \pm 5.1$ & 30,865 & $5.0 \pm 5.5$ & 9902 \\
\hline PtGA, cm & $4.6 \pm 2.6$ & 24,764 & $5.2 \pm 2.3$ & 9902 \\
\hline
\end{tabular}

Values are $\mathrm{n}(\%)$ or mean \pm SD. ACPA: anticitrullinated peptide antibodies; BMI: body mass index; bDMARD: biological disease-modifying antirheumatic drugs; HAQ: Health Assessment Questionnaire; N1 and N2: no. patients with information available; PtGA: patient's global assessment; PGA: physician's global assessment; RF: rheumatoid factor; SJC28: 28-joint swollen joint count; TJC28: 28-joint tender joint count.

based on the DAS, the percentages of visits with patients achieving remission ranged between $15.2 \%$ [for the newly proposed DAS28-ESR(3v) cutoff of 2.2] and 39.1\% [for the DAS-CRP(3v) cutoff of 1.6].

Remission data regarding the subset of visits with infor- mation on all definitions of remission are presented in Supplementary Table 2 (available with the online version of this article). Results for this subset of patients were similar to those described above.

Proportion of visits with patients with good functional status 
Table 2. Visits in remission according to different definitions of remission*.

\begin{tabular}{|c|c|c|c|c|c|}
\hline Definition of Remission & & \multicolumn{2}{|c|}{$\begin{array}{c}\text { Patients in Remission at } \\
\text { First METEOR Visit, } \mathrm{n}(\%)\end{array}$} & \multicolumn{2}{|c|}{$\begin{array}{l}\text { Visits in Remission, Taking All } \\
\text { Visits into Account, } \mathrm{n}(\%)\end{array}$} \\
\hline $\mathrm{SDAI} \leq 3.3$ & & $705(6.1)$ & 11,562 & $7072(17.1)$ & 41,420 \\
\hline $\mathrm{CDAI} \leq 2.8$ & & $1188(7.6)$ & 15,682 & $9579(13.4)$ & 71,790 \\
\hline DAS-CRP $<1.6$ & $4 \mathrm{v}$ & $2093(16.0)$ & 13,067 & $19,481(38.6)$ & 50,517 \\
\hline & $3 \mathrm{v}$ & $4238(18.6)$ & 22,780 & $33,774(30.4)$ & 111,149 \\
\hline \multirow[t]{2}{*}{ DAS28-CRP $<2.6$} & $4 \mathrm{v}$ & $2326(15.8)$ & 14,696 & $19,252(34.8)$ & 55,261 \\
\hline & $3 \mathrm{v}$ & $3097(16.3)$ & 19,049 & $24,742(37.5)$ & 65,944 \\
\hline \multirow[t]{2}{*}{ DAS28-ESR $<2.6$} & $4 \mathrm{v}$ & $3295(16.1)$ & 20,497 & $24,895(25.2)$ & 98,629 \\
\hline & $3 \mathrm{v}$ & $3765(14.9)$ & 25,235 & $28,647(24.4)$ & 117,404 \\
\hline DAS28-CRP $<1.9^{* *}$ & $4 \mathrm{v}$ & $1020(6.9)$ & 14,696 & $9328(16.9)$ & 55,261 \\
\hline DAS28-CRP $<2.4 * *$ & $3 \mathrm{v}$ & $2657(13.9)$ & 19,049 & $21,500(32.5)$ & 65,944 \\
\hline
\end{tabular}

* Results at the first METEOR visit and taking all visits into account. ** DAS28 formulae with the newly suggested cutoffs [DAS28-CRP $<1.9$ (calculated vs SDAI), DAS28-ESR < 2.2 (calculated vs SDAI), and DAS28-CRP < 2.4 (calculated vs DAS28-ESR)]. ACR: American College of Rheumatology; EULAR: European League Against Rheumatism; CDAI: Clinical Disease Activity Index; CRP: C-reactive protein; DAS: Disease Activity Score; DAS28: 28-joint count DAS; ESR: erythrocyte sedimentation rate; METEOR: Measurement of Efficacy of Treatment in the Era of Outcome in Rheumatology; N1 and N2: no. visits with information available; SDAI: Simplified Disease Activity Index; 3v: 3 variables; 4v: 4 variables.

Table 3. Visits in good functional status $(\mathrm{HAQ} \leq 0.5)$ according to remission status.

\begin{tabular}{|c|c|c|c|c|c|}
\hline Definition of Remission & & Yes & No & Yes & No \\
\hline \multicolumn{2}{|l|}{ ACR/EULAR Boolean-based } & $182(88.8)$ & $1868(29.3)$ & $1556(87.0)$ & $10,897(34.1)$ \\
\hline $\mathrm{CDAI} \leq 2.8$ & & $606(80.5)$ & $1364(25.1)$ & $4900(78.5)$ & $6775(27.4)$ \\
\hline \multirow[t]{2}{*}{ DAS-CRP $<1.6$} & $4 \mathrm{v}$ & $814(58.6)$ & $780(20.5)$ & $7826(59.1)$ & $3253(19.3)$ \\
\hline & $3 \mathrm{v}$ & $818(54.5)$ & $830(21.1)$ & $7836(56.4)$ & $3583(20.7)$ \\
\hline \multirow[t]{2}{*}{ DAS28-CRP $<2.6$} & $4 \mathrm{v}$ & $1056(64.6)$ & $994(20.1)$ & $8316(62.8)$ & $4137(20.2)$ \\
\hline & $3 \mathrm{v}$ & $1091(58.8)$ & $1024(20.5)$ & $8512(57.7)$ & $4301(21.3)$ \\
\hline \multirow[t]{2}{*}{ DAS28-ESR $<2.6$} & $4 \mathrm{v}$ & $1154(67.5)$ & $1863(25.8)$ & $8292(68.1)$ & $7828(26.5)$ \\
\hline & $3 \mathrm{v}$ & $1067(60.5)$ & $2041(27.0)$ & $7711(62.5)$ & $8851(28.7)$ \\
\hline \multirow[t]{2}{*}{ DAS28-CRP $<1.9^{*}$} & $4 \mathrm{v}$ & $567(75.3)$ & $1483(25.4)$ & $5002(74.8)$ & $7451(27.6)$ \\
\hline & $3 \mathrm{v}$ & $550(68.2)$ & $1565(25.9)$ & $4778(65.8)$ & $8035(29.1)$ \\
\hline
\end{tabular}

Values are n (\%). * DAS28 formulae with the newly suggested cutoffs [DAS28-CRP < 1.9 (calculated vs SDAI), DAS28-ESR < 2.2 (calculated vs SDAI), and DAS28-CRP < 2.4 (calculated vs DAS28-ESR)]. ** Percentages presented in each column are independent (not complementary) of the next-side column. ACR: American College of Rheumatology; EULAR: European League Against Rheumatism; CDAI: Clinical Disease Activity Index; CRP: C-reactive protein; DAS: Disease Activity Score; DAS28: 28-joint count DAS; ESR: erythrocyte sedimentation rate; HAQ: Health Assessment Questionnaire; METEOR: Measurement of Efficacy of Treatment in the Era of Outcome in Rheumatology; SDAI: Simplified Disease Activity Index; 3v: 3 variables; 4v: 4 variables.

among visits with and without disease activity remission status. As presented in Table 3, at first visit, the proportion of visits with $\mathrm{HAQ} \leq 0.5$ among patients in remission was higher for the most stringent definitions $(88.8 \%$ for
ACR/EULAR Boolean-based, $81.7 \%$ for SDAI, $80.5 \%$ for CDAI). A significant proportion of visits with patients in nonremission had HAQ $\leq 0.5$ (e.g., 29.3\% for ACR/EULAR Boolean-based definition, $21.6 \%$ of patients without SDAI

Personal non-commercial use only. The Journal of Rheumatology Copyright $\subset$ 2019. All rights reserved. 
remission, and $25.1 \%$ of patients without CDAI remission). The prevalence of good functional status in visits with patients fulfilling DAS/DAS28 remission definitions ranged from $54.5 \%$ [for DAS-CRP(3v) < 1.6] to $75.3 \%$ [for DAS28-CRP $(4 v)<1.9]$. Among visits with patients not fulfilling DAS/DAS28 remission, the proportion of patients with good functional status ranged from $20.1 \%$ [for patients not fulfilling DAS28-CRP $(4 \mathrm{v})<2.6$ ] to $30.1 \%$ [for patients not fulfilling DAS28-ESR $(3 v)<2.2]$. Similar results were obtained when all visits in the database were considered (Table 3 ) and when only patients with information available for all definitions of remission were considered (Supplementary Table 3 , available with the online version of this article).

A significant proportion of patients in remission reported HAQ scores $>0.5$ at the same visit (11.2-45.5\%) and a significant proportion of patients not in remission had HAQ scores $\leq 0.5$ (19.3-34.1\%). The proportion of patients not in remission who had $\mathrm{HAQ} \leq 0.5$ was higher for the most stringent definitions (Table 3 ).

Associations between remission and good functional status. The strongest association between remission and good functional state was observed for the SDAI definition of remission (OR 3.774, 95\% CI 3.492-4.078). Results were not divergent through the other definitions (Table 4), with the majority of $95 \%$ CI for the OR overlapping. Similar results were obtained when the model was adjusted for significant cofactors (SDAI adjusted OR 3.357, 95\% CI 3.012-3.742). Remission criteria based on DAS were more strongly associated with good functional status when $4 \mathrm{v}$ definitions were used (OR 4v between 2.778 and 3.365) compared to when $3 \mathrm{v}$ definitions were considered (OR 3v between 2.204 and 2.809). When CI of similar scores were compared, the lower limit of the OR for the $4 \mathrm{v}$ definition was always higher than the higher limit of the comparable $3 \mathrm{v}$ definition. A similar tendency was observed when adjusted OR were compared; however, some overlapping CI were observed.

When analyzing only visits with information available for all definitions of remission (Table 5), the SDAI definition of remission remained the most strongly associated with good functional status (OR 3.629, 95\% CI 3.338-3.945). Once again, DAS-based remission criteria presented a trend to be more associated with good functional status when $4 \mathrm{v}$ models were considered (OR 4v between 2.769 and 3.406), in comparison to $3 \mathrm{v}$ models (OR $3 \mathrm{v}$ between 2.248 and 3.016). However, overlaps between CI were observed for some definitions. In this analysis, when OR were adjusted for significant cofactors, the strongest association between remission and good functional status was observed for DAS-CRP(4v) $<1.6$ (OR 3.793, 95\% CI 3.354-4.289), followed by SDAI (OR 3.549, 95\% CI 3.107-4.053; Table 4).

Stringency of the newly proposed DAS28 remission cutoffs. As expected, the new cutoffs for DAS28 remission (DAS28-CRP $<1.9$ and DAS28-ESR $<2.2$ ) were associated with a lower percentage of visits in remission (range between $6.5 \%$ and $9.9 \%$ vs $14.9 \%$ and $16.3 \%$, respectively, at first visit; Table 2). However, the cutoffs were still less stringent than the ACR/EULAR Boolean-based or SDAI criteria $(1.9 \%$ and $6.1 \%$, respectively). Similar results were obtained when

Table 4. Longitudinal associations between good functional status (dependent variable) and remission (independent variable)*.

\begin{tabular}{|c|c|c|c|c|c|}
\hline \multirow{2}{*}{\multicolumn{2}{|c|}{ Definition of Remission }} & \multirow{2}{*}{\multicolumn{4}{|c|}{$\mathrm{HAQ} \leq 0.5$}} \\
\hline & & & & & \\
\hline ACR/EULAR Boolean- & & $\frac{\mathrm{N}}{33,709}$ & $\begin{array}{c}\text { Univariable OR }(95 \% \mathrm{CI}) \\
2.973(2.730-3.236)\end{array}$ & $\frac{N}{16,247}$ & $\frac{\text { Adjusted OR** }(95 \% \mathrm{CI})}{2.555(2.259-2.889)}$ \\
\hline $\mathrm{CDAI} \leq 2.8$ & & 30,977 & $3.659(3.417-3.920)$ & 15,137 & $3.152(2.855-3.481)$ \\
\hline \multirow[t]{2}{*}{ DAS-CRP $<1.6$} & $4 \mathrm{v}$ & 30,097 & $3.086(2.913-3.270)$ & 15,421 & $3.211(2.935-3.513)$ \\
\hline & $3 \mathrm{v}$ & 31,186 & $2.740(2.594-2.894)$ & 15,918 & $2.778(2.555-3.022)$ \\
\hline \multirow[t]{2}{*}{ DAS28-CRP $<2.6$} & $4 \mathrm{v}$ & 33,709 & $3.365(3.185-3.554)$ & 16,247 & $3.292(3.027-3.581)$ \\
\hline & $3 \mathrm{v}$ & 34,894 & $2.809(2.670-2.956)$ & 16,751 & $2.803(2.589-3.036)$ \\
\hline \multirow[t]{2}{*}{ DAS28-ESR $<2.6$} & $4 \mathrm{v}$ & 41,748 & $3.030(2.886-3.182)$ & 19,577 & $2.838(2.635-3.056)$ \\
\hline & $3 \mathrm{v}$ & 43,166 & $2.443(2.332-2.559)$ & 20,162 & $2.338(2.176-2.511)$ \\
\hline \multirow{2}{*}{ DAS28-CRP $<1.9^{* * *}$} & $4 \mathrm{v}$ & 33,709 & $3.050(2.874-3.237)$ & 16,247 & $2.799(2.571-3.048)$ \\
\hline & $3 \mathrm{v}$ & 34,894 & $2.400(2.274-2.533)$ & 16,751 & $2.256(2.089-2.436)$ \\
\hline
\end{tabular}

* Results for the entire set of visits. ** Adjusted OR for significant cofactors (age at visit, body mass index, female sex, rheumatoid factor positivity, presence of erosions, treatment with biologics). *** DAS28 formulae with the newly suggested cutoffs [DAS28-CRP < 1.9 (calculated vs SDAI), DAS28-ESR < 2.2 (calculated vs SDAI), and DAS28-CRP < 2.4 (calculated vs DAS28-ESR)]. ACR: American College of Rheumatology; EULAR: European League Against Rheumatism; CDAI: Clinical Disease Activity Index; CRP: C-reactive protein; DAS: Disease Activity Score; DAS28: 28-joint count DAS; ESR: erythrocyte sedimentation rate; HAQ: Health Assessment Questionnaire; SDAI: Simplified Disease Activity Index; 3v: 3 variables; 4 v: 4 variables.

Personal non-commercial use only. The Journal of Rheumatology Copyright $\odot$ 2019. All rights reserved. 
Table 5. Longitudinal associations between good functional status (dependent variable) and remission (independent variable)*.

\begin{tabular}{|c|c|c|c|}
\hline \multirow{2}{*}{\multicolumn{2}{|c|}{ Definition of Remission }} & \multicolumn{2}{|c|}{$\mathrm{HAQ} \leq 0.5$} \\
\hline & & $\begin{array}{c}\text { OR }(95 \% \mathrm{CI}), \mathrm{n}=20,808 \text { Visits; } \\
5548 \text { Patients }\end{array}$ & $\begin{array}{c}\text { Adjusted OR } * *(95 \% \mathrm{CI}), \\
\mathrm{n}=8431 \text { Visits; } 1799 \text { Patients }\end{array}$ \\
\hline \multicolumn{2}{|c|}{ ACR/EULAR Boolean-based } & $2.657(2.395-2.947)$ & $2.452(2.087-2.881)$ \\
\hline \multicolumn{2}{|l|}{$\mathrm{SDAI} \leq 3.3$} & $3.629(3.338-3.945)$ & $3.549(3.107-4.053)$ \\
\hline \multicolumn{2}{|l|}{$\mathrm{CDAI} \leq 2.8$} & $3.584(3.297-3.896)$ & $3.428(3.007-3.908)$ \\
\hline \multirow[t]{2}{*}{ DAS-CRP $<1.6$} & $4 v$ & $3.396(3.160-3.649)$ & $3.793(3.354-4.289)$ \\
\hline & $3 \mathrm{v}$ & $3.016(2.816-3.230)$ & $3.342(2.977-3.751)$ \\
\hline \multirow[t]{2}{*}{ DAS-ESR $<1.6$} & $4 v$ & $3.233(3.015-3.467)$ & $3.439(3.062-3.862)$ \\
\hline & $3 v$ & $2.798(2.615-2.994)$ & $3.026(2.706-3.383)$ \\
\hline \multirow[t]{2}{*}{ DAS28-CRP $<2.6$} & $4 v$ & $3.406(3.173-3.657)$ & $3.489(3.102-3.925)$ \\
\hline & $3 v$ & $2.866(2.680-3.065)$ & $3.052(2.729-3.413)$ \\
\hline \multirow[t]{2}{*}{ DAS28-ESR $<2.6$} & $4 v$ & $3.112(2.893-3.348)$ & $2.963(2.636-3.331)$ \\
\hline & $3 v$ & $2.487(2.323-2.663)$ & $2.483(2.217-2.781)$ \\
\hline \multirow[t]{2}{*}{ DAS28-CRP $<1.9 * * *$} & $4 v$ & $2.938(2.729-3.163)$ & $2.966(2.636-3.336)$ \\
\hline & $3 v$ & $2.276(2.128-2.434)$ & $2.371(2.127-2.645)$ \\
\hline \multirow[t]{2}{*}{ DAS28-ESR $<2.2 * * *$} & $4 v$ & $2.769(2.560-2.995)$ & $2.519(2.223-2.855)$ \\
\hline & $3 v$ & $2.248(2.082-2.427)$ & $2.059(1.823-2.324)$ \\
\hline \multirow[t]{2}{*}{ DAS28-CRP $<2.4 * * *$} & $4 v$ & $3.311(3.083-3.556)$ & $3.368(2.990-3.795)$ \\
\hline & $3 v$ & $2.704(2.530-2.889)$ & $2.815(2.523-3.142)$ \\
\hline
\end{tabular}

\footnotetext{
* Results considering only visits with data for all definitions of remission. ** Adjusted for age at visit, body mass index, female sex, rheumatoid factor positivity, presence of erosions, treatment with biologics. *** DAS28 formulae with the newly suggested cutoffs [DAS28-CRP $<1.9$ (calculated vs SDAI), DAS28-ESR $<2.2$ (calculated vs SDAI), and DAS28-CRP < 2.4 (calculated DAS28-ESR)]. ACR: American College of Rheumatology; EULAR: European League Against Rheumatism; CDAI: Clinical Disease Activity Index; CRP: C-reactive protein; DAS: Disease Activity Score; DAS28: 28-joint count DAS; ESR: erythrocyte sedimentation rate; HAQ: Health Assessment Questionnaire; SDAI: Simplified Disease Activity Index; 3v: 3 variables; 4v: 4 variables.
}

all visits were taken into account (Table 2). Their degree of association with good functional status (OR between 2.2 and 3.2) was similar to the older cutoffs (OR between 2.4 and 3.4).

\section{DISCUSSION}

This study confirmed the association between various remission definitions and physical function in a large international clinical practice setting. We found that the most stringent definition of remission was the ACR/EULAR Boolean-based definition and confirmed that the newly proposed DAS28 remission cutoffs (DAS28-CRP $<1.9$ and DAS28-ESR < 2.2) result in remission rates that are closer to the most stringent definitions. The proportion of patients with good functional status among those in remission was higher for the most stringent definitions. However, being in clinical remission was not always equivalent to having good functional status. Conversely, some patients not in remission had good functional status. The proportion of patients with good functional status among patients not in remission was typically higher when the most stringent definitions of remission were used.

The strongest degree of association between remission and good functional status was observed for the SDAI. However, differences between the various definitions were generally minor. Results were highly consistent in all the analyses performed, whether using first visits only, all visits, or only visits with complete data for all the 17 definitions of remission.

ACR/EULAR, CDAI, and SDAI remission criteria had already been described as the most stringent definitions of remission. In a German database with 6864 patients with RA, the percentages of remission according to DAS28-ESR $(4 \mathrm{v})$ $<2.6$, SDAI and ACR/EULAR Boolean-based definitions were $28.1 \%, 10.8 \%$, and $6.9 \%$, respectively ${ }^{21}$. CDAI criteria were not evaluated in that study. We found that CDAI remission criteria were more stringent than SDAI (when all visits were taken into account). In a paradigmatic clinical trial (the BeSt study), in which 508 RA patients with early disease were included, ACR/EULAR, CDAI, and SDAI remission criteria also classified a lower proportion of patients as being in remission compared to the indices based on DAS28. This study also demonstrated a positive association between remission and good functional status defined by a HAQ $\leq 0.5^{12}$.

A higher proportion of patients in good functional status was observed for the most stringent definitions (ACR/EULAR Boolean-based, $\mathrm{SDAI} \leq 3.3$, and $\mathrm{CDAI} \leq 2.8$ ). A tendency to a stronger association between remission and good functional status was observed for the SDAI definition. The OR obtained with different definitions were similar and CI overlapped. Remission criteria based on DAS presented a trend to be a stronger predictor of good functional status

Personal non-commercial use only. The Journal of Rheumatology Copyright (c) 2019. All rights reserved. 
when the $4 \mathrm{v}$ definitions were used. This was confirmed by sensitivity analyses and probably reflects the effect of functional status upon the PtGA score, included in the $4 \mathrm{v}$ definitions. This is in line with the observation by Ferreira, et $a l^{22}$ that PtGA in patients with RA is strongly associated with disease effect factors, such as function, fatigue, pain, and anxiety, and only weakly with disease activity. This is even more pronounced in patients who keep high PtGA scores in the absence of overt signs of inflammation.

As mentioned, despite the clear association between the two, remission does not always mean good functional status. Some previous studies suggest that coping strategies may contribute to the dissociation between remission and good functional status observed in a sizeable proportion of patients. Patients with effective coping tend to report a less-severe functional impairment in $\mathrm{RA}^{23}$ and in other rheumatic diseases ${ }^{24}$.

The new remission definitions for DAS $28^{14}$ confirmed in this setting a tendency to have a stronger association with good functional status than the previous ones. This may suggest that these definitions should be preferable. However, the argument is complex. When Thiele, et al compared patients with RA to a randomly matched sample from the general German population, they found that patients fulfilling DAS28-ESR(4v) remission criteria had a functional status identical to the matched controls, but those who fulfilled SDAI or Boolean-based remission criteria had a considerably better functional status than the matched controls ${ }^{21}$. This suggests that the new Boolean-based and SDAI criteria may select supernormal patients that are not only free from active RA but also from other comorbid conditions, and who have the most effective coping strategies. Because activity indices are used to guide clinical treatment decisions, it is important that clinicians are aware of this issue, to avoid overtreatment ${ }^{25}$. Patients with comorbid conditions, including other musculoskeletal conditions such as osteoarthritis and fibromyalgia, may never be able to meet the most stringent remission criteria, even if RA is brought under absolute control and has no functional effect of its own ${ }^{26}$. Patients with comorbidities, who represent the norm in clinical practice, will benefit more from guided treatments to the specific comorbidity than from immunosuppressive agents.

Our study included data from 32,915 patients and 157,899 visits from all around the world. This makes it the largest study ever performed addressing the current aims, to our knowledge, thanks to the METEOR multinational collaborative initiative. Further, 17 definitions of remission were analyzed and compared, which is also unprecedented. The statistical methods used allowed us to analyze a large number of timepoints simultaneously, while adjusting for within-patient correlation. Because data were collected from patients followed in regular clinics, there was a significant number of missing data. To account for possible selection bias, extensive sensitivity analyses were performed. In general, results were consistent across all the analyses. However, some limitations may also be considered, including the heterogeneity of the population, which may implicate genetic, social, and demographic differences that might have influenced the results in a manner that we cannot estimate or account for. The remission criteria studied in this paper and even HAQ were developed mostly in white patients and their validity in such different populations was not clearly established yet. When comparing results of different remission definitions, readers should be aware that a certain overlap between groups is present, as a patient may be simultaneously in remission according to different definitions. As patients were treated according to local standard of care, different treatments could influence remission rates. We considered biologic treatment as the main possible treatment confounder, and adjustment for biologic treatment was included in the multivariable models, yielding results similar to the unadjusted models; however, the effect of other treatments was not analyzed in this study.

The various remission definitions confirmed their association with physical function in a large prospective international clinical practice setting. In spite of this, importantly, many patients not in remission have good functional status, while being in clinical remission does not equate to having good functional status. A multidimensional approach should be taken to help patients achieve this functional goal. Achievement of remission according to any of the indices may be more important than the selection of a specific one.

\section{ACKNOWLEDGMENT}

We thank the Merit Board for all its support, and all METEOR investigators. We especially acknowledge Sytske-Anne Bergstra (Leiden, the Netherlands) and Rosaline van den Berg (Leiden, the Netherlands) for their support in database management.

\section{DATA AVAILABILITY}

The datasets generated and/or analyzed during the current study are not publicly available because of privacy policies but are available from the corresponding author on reasonable request.

\section{ONLINE SUPPLEMENT}

Supplementary material accompanies the online version of this article.

\section{REFERENCES}

1. Ramiro S, Machado P, Singh JA, Landewe RB, da Silva JA. Applying science in practice: The optimization of biological therapy in rheumatoid arthritis. Arthritis Res Ther 2010;12:220.

2. Mierau M, Schoels M, Gonda G, Fuchs J, Aletaha D, Smolen JS Assessing remission in clinical practice. Rheumatology 2007;46:975-9.

3. Ranganath VK, Khanna D, Paulus HE. ACR remission criteria and response criteria. Clin Exp Rheumatol 2006;6 Suppl 43:S-14-21.

4. Bergman MJ. Assessing adequate treatment response in patients with rheumatoid arthritis. Clin Ther 2009;31:1219-31.

5. Makinen H, Hannonen P, Sokka T. Definitions of remission for rheumatoid arthritis and review of selected clinical cohorts and randomised clinical trials for the rate of remission. Clin Exp Rheumatol 2006;6 Suppl 43:S-22-8. 
6. Martins FM, da Silva JA, Santos MJ, Vieira-Sousa E, Duarte C, Santos H, et al. DAS28, CDAI and SDAI cut-offs do not translate the same information: Results from the Rheumatic Diseases Portuguese Register Reuma.pt. Rheumatology 2015;54:286-91.

7. van Tuyl LH, Vlad SC, Felson DT, Wells G, Boers M. Defining remission in rheumatoid arthritis: Results of an initial American College of Rheumatology/European League Against Rheumatism consensus conference. Arthritis Rheum 2009;61:704-10.

8. Zhang B, Combe B, Rincheval N, Felson DT. Validation of ACR/EULAR definition of remission in rheumatoid arthritis from RA practice: the ESPOIR cohort. Arthritis Res Ther 2012;14:R156.

9. Svensson B, Andersson ML, Bala SV, Forslind K, Hafström I; BARFOT study group. Long-term sustained remission in a cohort study of patients with rheumatoid arthritis: choice of remission criteria. BMJ Open 2013;3:e03554.

10. Ajeganova $S$, Huizinga $T$. Sustained remission in rheumatoid arthritis: latest evidence and clinical considerations. Ther Adv Musculoskelet Dis 2017;9:249-62.

11. van Tuyl LH, Felson DT, Wells G, Smolen J, Zhang B, Boers M; American College of Rheumatology; European League against Rheumatism Committee to Define Remission for Clinical Trials. Evidence for predictive validity of remission on long-term outcome in rheumatoid arthritis: a systematic review. Arthritis Care Res 2010;62:108-17.

12. Klarenbeek NB, Koevoets R, van der Heijde DM, Gerards AH, Ten Wolde S, Kerstens PJ, et al. Association with joint damage and physical functioning of nine composite indices and the 2011 ACR/EULAR remission criteria in rheumatoid arthritis. Ann Rheum Dis 2011;70:1815-21.

13. Einarsson JT, Geborek P, Saxne T, Kristensen LE, Kapetanovic MC. Sustained remission improves physical function in patients with established rheumatoid arthritis, and should be a treatment goal: a prospective observational cohort study from southern Sweden. J Rheumatol 2016;43:1017-23.

14. Fleischmann R, van der Heijde D, Koenig AS, Pedersen R, Szumski A, Marshall L, et al. How much does Disease Activity Score in 28 joints ESR and CRP calculations underestimate disease activity compared with the Simplified Disease Activity Index? Ann Rheum Dis 2015;74:1132-7.

15. Fleischmann RM, van der Heijde D, Gardiner PV, Szumski A, Marshall L, Bananis E. DAS28-CRP and DAS28-ESR cut-offs for high disease activity in rheumatoid arthritis are not interchangeable. RMD Open 2017;3:e000382.

16. Bergstra SA, Machado PM, van den Berg R, Landewé RB, Huizinga TW. Ten years of METEOR (an international rheumatoid arthritis registry): development, research opportunities and future perspectives. Clin Exp Rheumatol 2016;5 Suppl 101:S87-S90.
17. Bergstra SA, Winchow LL, Murphy E, Chopra A, Salomon-Escoto $\mathrm{K}$, Fonseca JE, et al. How to treat patients with rheumatoid arthritis when methotrexate has failed? The use of a multiple propensity score to adjust for confounding by indication in observational studies. Ann Rheum Dis 2019;78:25-30.

18. Bergstra SA, Branco JC, Vega-Morales D, Salomon-Escoto K, Govind N, Allaart CF, et al. Inequity in access to bDMARD care and how it influences disease outcomes across countries worldwide: results from the METEOR-registry. Ann Rheum Dis 2018; 77:1413-20

19. Wells GA, Boers M, Shea B, Brooks PM, Simon LS, Strand CV, et al. Minimal disease activity for rheumatoid arthritis: a preliminary definition. J Rheumatol 2005;32:2016-24.

20. Twisk JW. Longitudinal data analysis. A comparison between generalized estimating equations and random coefficient analysis. Eur J Epidemiol 2004;19:769-76.

21. Thiele K, Huscher D, Bischoff S, Spathling-Mestekemper S, Backhaus M, Aringer M, et al; German Collaborative Arthritis Centres. Performance of the 2011 ACR/EULAR preliminary remission criteria compared with DAS28 remission in unselected patients with rheumatoid arthritis. Ann Rheum Dis 2013;72:1194-9.

22. Ferreira RJ, Duarte C, Ndosi M, de Wit M, Gossec L, da Silva JA. Suppressing inflammation in rheumatoid arthritis: does patient global assessment blur the target? A practice-based call for a paradigm change. Arthritis Care Res 2018;70:369-78.

23. Flurey CA, Hewlett S, Rodham K, White A, Noddings R, Kirwan JR. Coping strategies, psychological impact, and support preferences of men with rheumatoid arthritis: a multicentre survey. Arthritis Care Res 2018;70:851-60.

24. Peláez-Ballestas I, Boonen A, Vázquez-Mellado J, Reyes-Lagunes I, Hernández-Garduño A, Goycochea MV, et al; REUMAIMPACT group. Coping strategies for health and daily-life stressors in patients with rheumatoid arthritis, ankylosing spondylitis, and gout: STROBE-compliant article. Medicine 2015;94:e600.

25. Smolen JS, Landewe R, Bijlsma J, Burmester G, Chatzidionysiou K, Dougados M, et al. EULAR recommendations for the management of rheumatoid arthritis with synthetic and biological disease-modifying antirheumatic drugs: 2016 update. Ann Rheum Dis 2017;76:960-77.

26. Vega-Morales D, Lozano-Plata LI, Esquivel-Valerio JA. The effect size of fibromyalgia on PG-VAS in rheumatoid arthritis patients. Adjustment proposal in DAS28-ESR: letter to the editor regarding Challa, D.N.V., Crowson, C.S. \& Davis, J.M. Rheumatol Ther 2017;4:515-17. 